\title{
POSTURAL CONTROL OF SMALL FOR GESTATIONAL AGE INFANTS BORN AT TERM
}

\author{
Campos D ${ }^{1}$, Santos DCC ${ }^{2}$, Gonçalves VMG ${ }^{1}$, Montebelo MIL ${ }^{2}$, Goto MMF ${ }^{1}$ e GabBard C 3 \\ ${ }^{1}$ Programa de Pós-Graduação em Ciências Médicas, Faculdade de Ciências Médicas, Universidade Estadual de \\ Campinas, Campinas, SP - Brasil \\ ${ }^{2}$ Programa de Pós-Graduação em Fisioterapia, Faculdade de Ciências da Saúde, Universidade Metodista de Piracicaba, \\ Piracicaba, SP - Brasil \\ ${ }^{3}$ Department of Health and Kinesiology, Texas A\&M University, Texas - EUA \\ Correspondence to: Profa. Dra. Denise Castilho Cabrera Santos, PPG em Fisioterapia, Universidade Metodista de \\ Piracicaba (UNIMEP), Rodovia do Açúcar Km 156, Bloco 07, Sala 46, CEP 13400-911, Piracicaba, SP - Brasil, \\ e-mail: dcsantose@unimep.br
}

Received: 28/11/2005 - Revised: 12/05/2006 - Accepted: 16/10/2006

\begin{abstract}
Objective: This study compared the postural control of small (SGA) and appropriate (AGA) for gestational age infants born at term, at the ages of 3, 6, 9 and 12 months. Method: This was a cohort study of infants born at term, with birth weight less than the $10^{\text {th }}$ percentile for the SGA group and between the $10^{\text {th }}$ and $90^{\text {th }}$ percentiles for the AGA group. Infants with genetic syndromes, malformations, congenital infections and internment in neonatal intensive care unit were excluded. The evaluation instrument was the Alberta Infant Motor Scale. Results: Comparison of the SGA and AGA groups did not show any significant differences $(\mathrm{p}>0.05)$ at the assessment times. However, the postural control of the SGA group was influenced by the gestational age $(r=-0.83 ; p=0.006)$ and $5^{\text {th }}$ minute Apgar $(r=0.79 ; p=0.01)$ in the $3^{\text {rd }}$ month, and by maternal occupation $(r=0.67 ; p=0.01)$ in the $6^{\text {th }}$ month. Conclusion: It was concluded that the postural control was similar in the groups. However, the postural control of the SGA group was influenced by biological and environmental factors.
\end{abstract}

Key words: infant, fetal growth retardation, child development.

\section{RESUMO}

\section{Controle Postural de Lactentes Nascidos a Termo Pequenos para a Idade Gestacional}

Objetivo: Este estudo teve por objetivo comparar o controle postural de lactentes nascidos a termo, pequenos (PIG) e adequados para a idade gestacional (AIG) nos $3^{\circ}, 6^{\circ}, 9^{\circ}$ e $12^{\circ}$ meses. MÉTODO: Estudo longitudinal de lactentes nascidos a termo, com peso de nascimento menor que o percentil 10 para o grupo PIG e entre o percentil 10 e 90 para o grupo AIG. Síndromes genéticas, más-formações, infecções congênitas e internados em unidade de terapia intensiva neonatal foram excluídos. O instrumento de avaliação foi Alberta Infant Motor Scale. Resultados: A comparação do grupo PIG e AIG não mostrou diferença significativa $(\mathrm{p}>0,05)$ nos meses avaliados. Entretanto, o controle postural do grupo PIG foi influenciado pela idade gestacional $(\mathrm{r}=-0,83 /$ $\mathrm{p}=0,006)$ e Apgar de 5' $(\mathrm{r}=0,79 / \mathrm{p}=0,01)$ no $3^{\circ}$ mês; e pela ocupação materna $(\mathrm{r}=0,67 / \mathrm{p}=0,01)$ no $6^{\circ}$ mês. Conclusão: Concluiu-se que o controle postural foi similar nos grupos; porém o controle postural do grupo PIG foi influenciado por fatores biológicos e ambientais.

Palavras-chave: lactente, retardo do crescimento fetal, desenvolvimento infantil. 


\section{INTRODUCTION}

Worldwide, newborns with low birth weight (LBW) represent $17 \%$ of births ${ }^{1}$. In developed countries, LBW typically occurs due to preterm delivery. In contrast, in developing countries the majority of LBW cases are full-term infants who have experienced intrauterine growth restriction $(\text { IUGR })^{2}$.

IUGR is said to have occurred when, at birth, the infant has not achieved its genetic growth potential. In spite of the logic of this definition, it is little used in clinical practice, because of the difficulty in identifying each individual's genetic potential. Consequently, the clinical diagnosis of IUGR usually refers to infants who were born small for gestational age (SGA), i.e. with birth weight less than the $10^{\text {th }}$ percentile for the gestational age ${ }^{3}$.

Small babies are known to be at increased risk for a wide range of difficulties ${ }^{4}$. Some studies have shown that, in preschool and school age populations, SGA children present minor neurological signs, poor school performance ${ }^{5}$, fine motor coordination abnormalities, spatial relation deficits and poor visual-motor integration ${ }^{6-8}$.

However, from the clinical perspective of early detection and intervention, the challenge of identifying the way IUGR acts on infants' development continues. Within the context that the prevalence of LBW is high in Brazil $(9 \%)^{9}$, the aim of the present study was to compare the postural control of SGA and AGA (appropriate for gestational age) infants born at term in their $3^{\text {rd }}, 6^{\text {th }}, 9^{\text {th }}$ and $12^{\text {th }}$ months of life.

\section{METHOD}

The present study was part of a cohort study that compared the neurodevelopment of a full-term SGA group and an AGA control group in the $3^{\text {rd }}, 6^{\text {th }}$, $9^{\text {th }}$ and $12^{\text {th }}$ months of life. Postural control was one of the characteristics observed in both groups.

From May 2000 to July 2003, a neonatologist selected 44 full-term SGA and AGA neonates who were delivered at the Neonatology Service of the Comprehensive Women's Healthcare Center (CAISM) of the State University of Campinas (UNICAMP), São Paulo, Brazil. When one SGA neonate was selected, two AGA neonates were also selected. The families of the neonates selected were invited to bring them for assessment every three months during the first year of life. Ethical approval was obtained from the Research Ethics Committee of the School of Medical Sciences of UNICAMP (087/03) and the mothers gave their fully informed consent. The subjects were selected using the following criteria: 1) living in the Campinas metropolitan area; 2) considered to be in good health, such that they could go home within two days of birth; 3) gestational age categorized as full-term (37-41 weeks) via the Capurro method; and 4) expected birth weight categorized via the Lubchenco method: birth weight less than the 10th percentile for the SGA group and between the $10^{\text {th }}$ and $90^{\text {th }}$ percentiles for the AGA group. Neonates with genetic syndromes, multiple congenital malformations and verified congenital infections (syphilis, toxoplasmosis, rubella, cytomegalovirus and herpes) were excluded.

All the children were assessed in the presence of their mothers at 3, 6, 9 and 12 months of age. The latitude allowed was seven days before or after the respective assessment age. The Alberta Infant Motor Scale (AIMS) ${ }^{10}$ was applied by two physical therapists (one of them was the main tester and the other was the observer) who were unaware of which group each neonate had been classified in. The scores for the infants' performances were obtained by agreement between the two testers.

The AIMS requires minimal handling of the infants and has been recognized as a sensitive instrument for detecting abnormalities in at-risk infants ${ }^{10}$. It contains 58 items that illustrate the developmental sequence of postural control in four positions: prone (21 items), supine (9 items), sitting (12 items) and standing (16 items). Total assessment scores were obtained by summing the observed items in the four positions. Each infant was then classified on a developmental curve that ranged from the $5^{\text {th }}$ to the $90^{\text {th }}$ percentile. The AIMS development curve represents the data from normal Canadian infants; and in the present study it served as the basis for comparison between the SGA and AGA groups.

Statistical analyses were performed using the Statistical Package for Social Sciences for Personal Computer (SPSS/ PC 11.0). The probability level adopted for rejection of the null hypothesis was $\mathrm{p}<0.05$.

The SGA and AGA groups were characterized by means of descriptive statistics using numerical variables (birth weight, gestational age and $1^{\text {st }}$ and $5^{\text {th }}$ minute Apgar scores) summarized as position and dispersion measurements. The categorical variables (maternal age, maternal education, maternal occupation, marital status and per capita income) were analyzed using frequencies. The groups were compared using the Mann-Whitney test for the numerical variables and the chi-squared or Fisher test for categorical data. The postural control characteristics of the two groups were compared each month using the Mann-Whitney test. Correlations between newborn and family variables and postural control were determined using the Spearman correlation coefficient.

\section{RESULTS}

A total of 44 infants (14 SGA and 30 AGA) were assessed at least two times from the $3^{\text {rd }}$ to $12^{\text {th }}$ month. The sample consisted of 27 infants (9 SGA and 18 AGA) in the $3^{\text {rd }}$ month, 38 infants (12 SGA and 26 AGA) in the $6^{\text {th }}$ month, 37 infants (11 SGA and 26 AGA) in the $9^{\text {th }}$ month, and 35 infants (10 SGA and 25 AGA) in the $12^{\text {th }}$ month. Fourteen infants were evaluated on all four occasions, twenty were evaluated on three occasions and ten on two occasions. The variation in 
Table 1. Characteristics of SGA and AGA groups at birth.

\begin{tabular}{cccccccc}
\hline Newborn Variables & Group & n & Minimum & Maximum & Mean & SD & p-value $^{\text {a }}$ \\
\hline \multirow{2}{*}{ BW (g) } & SGA & 14 & 2180 & 2620 & 2408,93 & 164,35 & \multirow{2}{*}{ (g,001 } \\
& AGA & 30 & 2635 & 3850 & 3142,17 & 318,29 & \\
\multirow{2}{*}{ GA (wk) } & SGA & 14 & 38,5 & 41,1 & 39,9 & 0,86 & 0,917 \\
& AGA & $29 *$ & 37,4 & 41,8 & 39,8 & 1,07 & \\
1' Apgar & SGA & $13^{*}$ & 3 & 10 & 8,2 & 1,69 & 0,123 \\
& AGA & $27 *$ & 1 & 10 & 7,6 & 1,90 & \\
5' Apgar & SGA & $13^{*}$ & 8 & 10 & 9,3 & 0,65 & 0,820 \\
& AGA & $27 *$ & 8 & 10 & 9,4 & 0,58 & \\
\hline
\end{tabular}

$\overline{\mathrm{SGA}}=$ small for gestational age; A $\overline{G A}$ = appropriate for gestational age; $\mathrm{BW}=$ birth weight; $\mathrm{g}$ = grams; $\mathrm{GA}$ = gestational age; $w \mathrm{k}$ = weeks; $\mathrm{n}$ = number of infants; SD = standard deviation; (a) = Mann-Whitney Test; * = missing information.

Table 2. Family characteristics of the SGA and AGA group.

\begin{tabular}{|c|c|c|c|}
\hline Family Variables & $\begin{array}{l}\text { SGA } \\
\text { f (\%) }\end{array}$ & $\begin{array}{l}\text { AGA } \\
\text { f (\%) }\end{array}$ & p-value \\
\hline \multicolumn{4}{|l|}{ Maternal Age (years) } \\
\hline$<20$ & $2(14,3)$ & $7(23,3)$ & \multirow{2}{*}{$0,695^{b}$} \\
\hline$\geq 20$ & $12(85,7)$ & $23(76,7)$ & \\
\hline \multicolumn{4}{|l|}{ Maternal Education (years of study) * } \\
\hline$<8$ & $9(64,3)$ & $11(37,9)$ & \multirow{2}{*}{$0,104^{c}$} \\
\hline$\geq 8$ & $5(35,7)$ & $18(62,1)$ & \\
\hline \multicolumn{4}{|l|}{ Maternal Occupation } \\
\hline Mothers without work out of the home & $11(78,6)$ & $16(53,3)$ & \multirow{2}{*}{$0,109^{c}$} \\
\hline Mothers with work out of the home & $3(21,4)$ & $14(46,7)$ & \\
\hline \multicolumn{4}{|l|}{ Mother's Marital Status* } \\
\hline Not married & $3(23,1)$ & $3(11,1)$ & \multirow{2}{*}{$0,370^{\mathrm{b}}$} \\
\hline Married & $10(76,9)$ & $24(88,9)$ & \\
\hline \multicolumn{4}{|l|}{ Income Per Capita (minimum salaries) * } \\
\hline$<0,50$ & $6(66,7)$ & $11(39,3)$ & \multirow{2}{*}{$0,251^{\mathrm{b}}$} \\
\hline$\geq 0,50$ & $3(33,3)$ & $17(60,7)$ & \\
\hline
\end{tabular}

SGA = small for gestational age; AGA $=$ appropriate for gestational age; $\mathrm{f}=$ absolute frequency; \% = relative frequency; (b) = Fisher Test; (c) = Chi-Square Test; $*$ = missing information.

the number of infants assessed on each occasion occurred because the parents did not bring them for assessment.

The newborn and family characteristics of the SGA and AGA groups are shown in Tables 1 and 2 respectively. Comparison of the groups showed that there was a significant difference in birth weight. The other newborn variables did not present any significant difference. These results demonstrate the effectiveness of the method used for subject selection and classification into the groups. Moreover, the groups had similar compositions with regard to the family data. This indicates the homogeneity of the groups studied.

Figure 1 displays the evolution curve for the groups, considering the median percentiles of the groups at each evaluation time. In comparison with the AGA group, the development of the SGA group presented a decline that was most accentuated in the $6^{\text {th }}$ month. However, there was no 


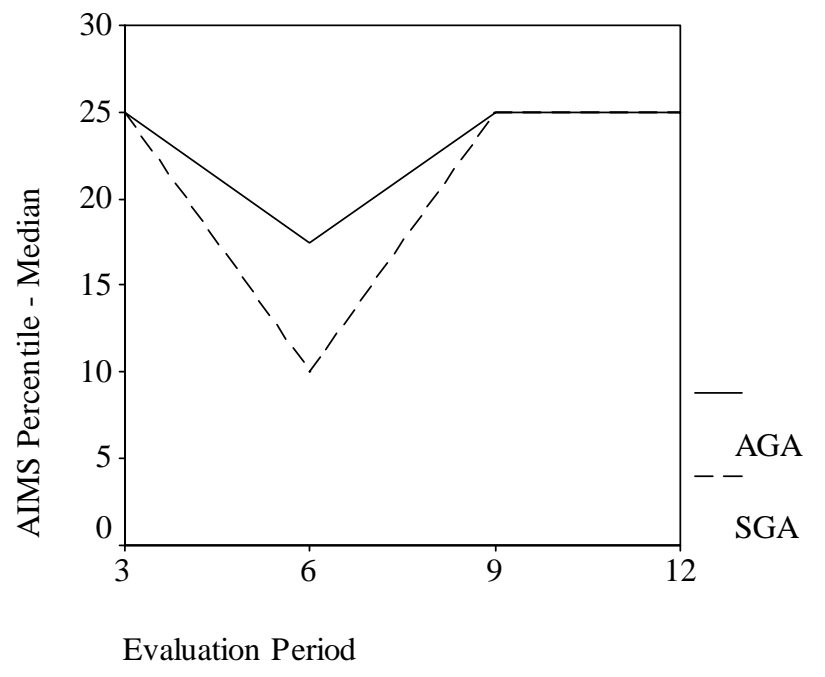

Figure 1. Evolution curves of the SGA and AGA group.

significant difference in motor performance between the SGA and AGA groups at the assessment months. This analysis can be seen in Table 3 .

The correlation analysis showed that the percentile of the SGA group was strongly influenced by the gestational age $(\mathrm{r}=-0.83 ; \mathrm{p}=0.006)$ and the $5^{\text {th }}$ minute Apgar score $(r=0.79 ; p=0.01)$ in the $3^{\text {rd }}$ month, and moderately influenced by the maternal occupation $(r=0.67 ; p=0.01)$ in the $6^{\text {th }}$ month. On the other hand, in the AGA group, no newborn or family variable presented a significant correlation.

\section{DISCUSSION}

The present study evaluated the postural control of a group of SGA and AGA infants born at term and assessed

Table 3. Percentile Comparison of SGA with AGA group.

\begin{tabular}{ccccc}
\hline Period & Group & n & Mean Rank p-value \\
& & & & \\
\hline $3^{\circ}$ month & SGA & 9 & 14,22 & \\
& AGA & 18 & 13,89 & 0,916 \\
& SGA & 12 & 18,25 & \\
$6^{\circ}$ month & AGA & 26 & 20,08 & 0,625 \\
& SGA & 11 & 17,91 & \\
$9^{\circ}$ month & AGA & 26 & 19,46 & 0,677 \\
& SGA & 10 & 18,00 & \\
$12^{\circ}$ month & AGA & 25 & 18,00 & 1,000 \\
& & &
\end{tabular}

$\overline{\mathrm{SGA}}=$ small for gestational age; $\mathrm{AGA}=\overline{\text { appropriate }}$ for gestational age; $\mathrm{n}=$ number of infants; (d) = Mann-Whitney Test. in the $3^{\text {rd }}, 6^{\text {th }}, 9^{\text {th }}$ and $12^{\text {th }}$ months of life. The primary aim of the study was to verify whether IUGR altered the normal acquisition of postural control.

It is important to emphasize that great difficulty exists in comparing studies on the repercussions of IUGR in infant development. This difficulty is due to the heterogeneity of the groups from one study to another. In some previous studies, it was suggested that newborns with risk factors for developmental abnormalities should not be excluded and in others, SGA preterm newborns were included, a variety of developmental characteristics were investigated and different ages were assessed ${ }^{11}$.

The comparison of postural control between the SGA and AGA groups in the $3^{\text {rd }}, 6^{\text {th }}, 9^{\text {th }}$ and $12^{\text {th }}$ months did not show any significant difference (Table 3 ). It should be noted that the infants studied were born SGA at term, and did not present any other disorder (Table 1).

Several studies evaluating term IUGR neonates have indicated that, even though there is an increased risk of physical, intellectual, neurological and behavioral disability, the majority of these infants are found to be normal upon follow-up. According to Westwood et al. ${ }^{12}$, in the absence of perinatal hypoxia-related factors, IUGR is not associated with higher risk of neurological morbidity. In the present study, the SGA group did not show perinatal hypoxia (Table 1). This may be one of the reasons why the groups did not differ in their levels of postural control.

It has been speculated that children's motor development in the presence of minor neuromotor abnormalities would proceed in the same sequence as in normal children. However, many components are lost, such as ability, harmony and speed $^{13}$. According to Van Kranen-Mastenbroek et al. ${ }^{14}$, SGA term infants may show differences relating to movement quality, in comparison with AGA infants. However, it is possible that such differences are not evident when the quantitative aspects of postural control are analyzed.

It should be noted that, even though the groups did not show differences during the first year of life (Table 3), this does not rule out the possibility of inadequate performance at subsequent ages. The literature indicates that, although motor problems are subtle at an early age, they tend to become more apparent as the children grow older ${ }^{5}$.

It is clear from the literature that fine motor development is one of the characteristics that is most affected in cases of early malnutrition ${ }^{15}$. Although there is evidence that postural control is related to fine motor function, some authors disagree. In the study by Darrah et al. ${ }^{16}$, postural control and fine motor function presented low correlation coefficients, thus suggesting that those two motor areas develop independently. Therefore, although the SGA term infants in the present study did not show any alteration in postural control, problems could arise in fine motor function. Therefore, we would agree that the assessment of postural 
control is insufficient to detect whether infants will develop fine motor deficits over time.

One matter that deserves mention is the identification of the beginning and duration of IUGR. Roth et al. ${ }^{17}$ demonstrated that the growth pattern in the third trimester of gestation does not affect the outcome for term infants with birth weight less than the $10^{\text {th }}$ percentile for GA. In the present study, these parameters (beginning and duration of IUGR) were not controlled for. However, since the SGA group did not differ from the AGA group in postural control (Table 3), it can be assumed that the IUGR occurred at a later phase of the gestation and did not affect those infants seriously.

Another point that needs to be discussed is the definition of SGA. In our study, SGA was defined as birth weight less than the $10^{\text {th }}$ percentile. However, this cutoff point may be too high to identify the population that is at risk of motor development abnormalities. It has been suggested that, among the infants who are usually defined as SGA, 22\% in fact appear to be constitutionally small, with a genetic growth potential that is lower than the statistical average ${ }^{18}$. According to McIntire et al. ${ }^{19}$, only the smallest infants ( $\leq 3^{\text {rd }}$ percentile) demonstrate increased neonatal mortality or morbidity.

The outcomes from the present study corroborate other studies that investigated the influence of IUGR on motor development and also did not show significant differences between the SGA group and the control group ${ }^{20,21}$. In the study by Markestad et al. ${ }^{20}$, the SGA $(n=265)$ and AGA $(n=329)$ term infants were compared in the $13^{\text {th }}$ month and presented similar motor performance. Newman et al. ${ }^{21}$ compared the neuromotor development of 65 SGA infants (birth weight below the $3^{\text {rd }}$ percentile) with 71 AGA infants. The results did not show any significant difference between the groups in the $4^{\text {th }}$ month of life.

Although in the present study we did not find differences between the groups, two recent reports have indicated divergences in development. Goto et al. ${ }^{22}$ compared the neurodevelopment of AGA and SGA infants in the second month of life and found that the SGA group scored significantly lower in mental and motor evaluation.

Peng et al. ${ }^{23}$ compared the growth and neurodevelopment of low birth weight (LBW) and normal birth weight (control) infants born in China and found that SGA infants presented lower weight and smaller head circumference than control subjects until the age of 16 years, shorter height until the age of 4 years, lower developmental quotient until the age of 3 years, lower intelligence quotient at the ages of 5 and 16 years, and lower scholastic achievement at the age of 16 years.

Another result obtained in the present study that deserves attention was the significant association of newborn and family variables with postural control. It appears that, in the group of SGA infants born at term, there was an inverse proportional relationship between the gestational age and the $3^{\text {rd }}$ month percentile. This suggests that the longer the pregnancy continues, the greater the duration of the intra-uterine restriction will be. This is in line with the findings of Ounsted, Moar and Scott ${ }^{6}$, who reported that the developmental scores of SGA children aged 4 and 7 years were inversely related to the duration of the pregnancy and therefore to the duration of starvation.

The directly proportional relationship between the $5^{\text {th }}$ minute Apgar score and the $3^{\text {rd }}$ month percentile in the SGA group can be explained by the evolution of the newborns' vitality. This suggests that better and faster adaptation to the extrauterine environment during the neonatal period would influence motor performance positively in infants that suffered IUGR. However, since the $5^{\text {th }}$ minute Apgar score oscillated within the limits of normality (Table 1 ), this statistical finding has no clinical significance.

The finding that mothers that work outside of the home positively influenced the percentile of the SGA infant in the $6^{\text {th }}$ month, leads to a discussion regarding environmental (sociocultural) influence. Parents tend to be overprotective and cautious when their children present some biological risk, like birth weight that is lower than expected. It is probable that the infants in the SGA group whose mothers did not work outside of the home stayed at home for most of the day, and this may have given rise to greater motor restriction (held by an adult, or in the baby carriage or baby-chair). We agree with $\mathrm{Bly}^{24}$ that such conditions can harm the learning process and the use of feedback and feedforward systems, which are essential for the acquisition of motor abilities.

When mothers work outside of the home, the childcare is delegated to day care centers or schools for most of the day. It is possible that, in these environments, infants are less restricted and more free movement is allowed. It should be pointed out, however, that in the SGA group only three mothers worked outside of the home (Table 2). Therefore, there is a need for more studies that investigate the relationship between maternal occupation and motor performance in a larger sample.

Unlike in the SGA group, in the AGA group no newborn or family variable influenced the outcomes at the evaluation times. These results are in agreement with other recent studies that have shown that the motor development of LBW term infants is more affected by biological, environmental and/ or socioeconomic adverse conditions than is the motor development of infants born at term with appropriate weight ${ }^{25,26}$.

The present study has certain limitations that need to be taken into account when considering the study and its contributions. First, although the cohort design allow for changes over time; the variation in the number of infants assessed on each month could limit the observation of postural control evolution. Second, the sample size could at least in part influence the results, including the correlations between newborn and family variables and postural control. A larger sample should be considered in future research. Third, there are conflicting results regarding neurodevelopment of infants 
exposed to IUGR, because of the heterogeneity of the groups studied (inclusion of premature newborns), the assessment instruments and the duration of the follow-up period ${ }^{11}$. The design of future studies on the subject of neurodevelopment of SGA infants should consider these limitations.

The comparison of postural control in the SGA and AGA groups did not show any significant differences in the $3^{\text {rd }}$, $6^{\text {th }}, 9^{\text {th }}$ and $12^{\text {th }}$ months. However, for the SGA group there was a significant effect in the $3^{\text {rd }}$ month, influenced by the gestational age and the $5^{\text {th }}$ minute Apgar score, and in the $6^{\text {th }}$ month, influenced by maternal occupation. For further investigation, it will be interesting to analyze both, postural and fine motor development of SGA and AGA groups.

\section{REFERENCES}

1. World Health Organization. Progress toward health for all: third monitoring report. World Health Stat Q. 1995;48(3-4):173-306.

2. Villar J, Belizán J. The relative contributions of prematurity and fetal growth retardation to low birth weight in developing and developed countries. Am J Obstet Gynecol. 1982;143:793-8.

3. Chard T, Yoong A, MacIntosh M. The myth of fetal growth-retardation at term. BJOG. 1993;100:1076-81.

4. Basso O, Frydenberg M, Olsen SF, Olsen J. Two definitions of "small size at birth" as predictors of motor development at six months. Epidemiology. 2005;16(5):657-63.

5. Walther FJ. Growth and development of term disproportionate small-for-gestational age infants at the age of 7 years. Early Hum Dev.1988;18:1-11.

6. Ounsted M, Moar VA, Scott A. Small-for-dates babies, gestational age, and developmental ability at 7 years. Early Hum Dev. 1989;19(2):77-86.

7. Sommerfelt K, Sonnander K, Skranes J, Andersson HW, Ahlsten G, Ellertsen B, et al. Neuropsychologic and motor function in small-for-gestation preschoolers. Pediatr Neurol. 2002;26(3): 186-91.

8. Gabbard C, Gonçalves VMG, Santos DCC. Visual-motor integration problems in low birth weight infants. J Clin Psychol Med Settings. 2001;8(3):199-204.

9. World Health Organization. The incidence of low birth weight: an update. Weekly Epidem Rec. 1984;59:205-11.

10. Piper MC, Darrah JM. Motor assessment of the developing infant. Philadelphia: WB Saunders Company; 1994.

11. Bos AF, Einspieler C, Prechtl HFR. Intrauterine growth retardation, general movements, and neurodevelopmental outcome: a review. Dev Med Child Neurol. 2001;43:61-8.

12. Westwood M, Kramer MS, Munz D, Lovett JM, Watters GV. Growth and development of full-term non-asphyxiated small-for-gestational-age newborns: follow-up through adolescence. Pediatrics. 1983;71(3):376-82.
13. Marcondes E. Pediatria básica. 8ª ed. São Paulo: Savier; 1994.

14. Van Kranen-Mastenbroek VHJM, Kingma H, Caberg HB, Ghys A, Blanco CE, Hasaart THM, et al. Quality of spontaneous general movements in full-term small for gestational age and appropriate for gestational age newborn infants. Neuropediatrics. 1994;25:145-53.

15. Vazir S, Naidu NA, Vidyasagar P. Nutritional status, psychosocial development and home environment of Indian rural children. J Indian Acad Pediatr. 1998;35:959-66.

16. Darrah J, Hodge M, Magill-Evans J, Kembhavi G. Stability of serial assessment of motor and communication abilities in typically developing infants - implications for screening. Early Hum Dev. 2003;72(2):97-110.

17. Roth S, Chang TC, Robson S, Spencer JAD, Wyatt JS, Stewart AL. The neurodevelopmental outcome of term infants with different intrauterine growth characteristics. Early Hum Dev. 1999;55:39-50.

18. Mamelle N, Cochet V, Claris O. Definition of fetal growth restriction according to constitutional growth potential. Biol Neonate. 2001;80:277-85.

19. McIntire DD, Bloom SL, Casey BM, Leveno KJ. Birth weight in relation to morbidity and mortality among newborn infants. N Engl J Med. 1999;340:1234-8.

20. Markestad T, Vik T, Ahlsten G, Gebre-Medhin M, Kksjaerven R, Jacobsen G, et al. Small-for-gestational-age (SGA) infants born at term: growth and development during the first year of life. Acta Obstet Gynecol Scand. 1997;76 Suppl 165:93-101.

21. Newman DG, O’Callaghan MJ, Harvey JM, Tudehope DI, Gray $\mathrm{PH}$, Burns VR, et al. Characteristics at four months follow-up of infants born small for gestational age: a controlled study. Early Hum Dev. 1997;49:169-81.

22. Goto MM, Goncalves VM, Netto AA, Morcillo AM, Moura-Ribeiro MV. Neurodevelopment of full-term small-for-gestational age infants in the second month of life. Arq Neuropsiquiatr. 2005;63:75-82.

23. Peng Y, Huang B, Biro F, Feng L, Guo Z, Slap G. Outcome of low birthweight in China: a 16-year longitudinal study. Acta Paediatr. 2005;94(7):843-9.

24. Bly L. What is the role of sensation in motor learning? What is the role of feedback and feedforward? NDTA Network. 1996; Sep-Oct: 3-8.

25. Grantham-McGregor SM, Lira PIC, Ashworth A, Morris SS, Assunção AMS. The development of low birth weight term infants and the effects of the environment in northeast Brazil. J Pediatr. 1998;32:661-6.

26. Eickmann SH, Lira PIC, Lima MC. Desenvolvimento mental e motor aos 24 meses de crianças nascidas a termo com baixo peso. Arq Neuropsiquiatr. 2002;60(3b):748-54. 